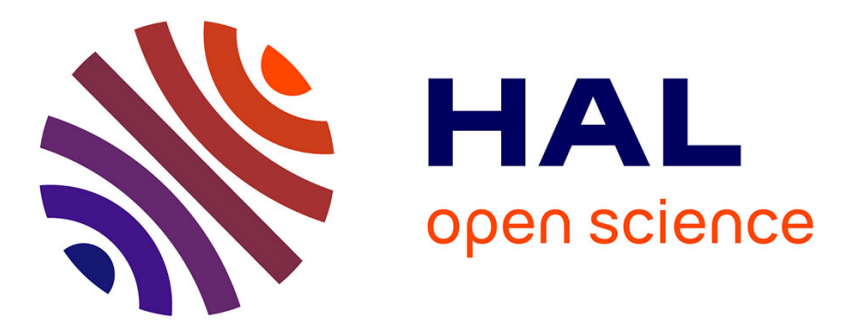

\title{
Use of experimental designs for the optimization of stir bar sorptive extraction coupled to GC-MS/MS and comprehensive validation for the quantification of pesticides in freshwaters
}

\author{
A. Assoumani, C. Margoum, C. Guillemain, Marina Coquery
}

\section{To cite this version:}

A. Assoumani, C. Margoum, C. Guillemain, Marina Coquery. Use of experimental designs for the optimization of stir bar sorptive extraction coupled to GC-MS/MS and comprehensive validation for the quantification of pesticides in freshwaters. Analytical and Bioanalytical Chemistry, 2014, 406 (11), p. 2559 - p. 2570 . 10.1007/s00216-014-7638-6 . hal-00996886

\section{HAL Id: hal-00996886 https://hal.science/hal-00996886}

Submitted on 27 May 2014

HAL is a multi-disciplinary open access archive for the deposit and dissemination of scientific research documents, whether they are published or not. The documents may come from teaching and research institutions in France or abroad, or from public or private research centers.
L'archive ouverte pluridisciplinaire HAL, est destinée au dépôt et à la diffusion de documents scientifiques de niveau recherche, publiés ou non, émanant des établissements d'enseignement et de recherche français ou étrangers, des laboratoires publics ou privés. 
1 Use of experimental designs for the optimization of stir bar sorptive 2 extraction coupled to GC-MS/MS and comprehensive validation for the 3 quantification of pesticides in freshwaters

\author{
4 A. Assoumani*, C. Margoum, C. Guillemain, M. Coquery
}

Irstea, UR MALY, 5 rue de la Doua, CS70077, F-69626, Villeurbanne Cedex, France

*Corresponding author: Tel: + 33472010 86; Fax: + 3347847 78 75; Email address: azziz.assoumani@irstea.fr

\title{
Abstract
}

Although experimental design is a powerful tool, it is rarely used for the development of analytical methods for the determination of organic contaminants in the environment. When investigated factors are interdependent, this methodology allows studying efficiently not only their effects on the response, but also the effects of their interactions. A complete and didactic chemometric study is described herein for the optimization of an analytical method involving stir bar sorptive extraction followed by thermal desorption coupled with gas chromatography and tandem mass spectrometry (SBSE-TD-GC-MS/MS) for the rapid quantification of several pesticides in freshwaters. We studied, under controlled conditions, the effects of thermal desorption parameters and the effects of their interactions on the desorption efficiency. The desorption time, temperature, flow, and the injector temperature were optimized through a screening design and a Box Behnken design. The two sequential designs allowed establishing an optimum set of conditions for maximum response. Then, we present the comprehensive validation and the determination of measurement uncertainty of the optimized method. Limits of quantification determined in different natural waters were in the range of $2.5 \mathrm{ng} \mathrm{L}^{-1}$ to 50 ng $\mathrm{L}^{-1}$ and recoveries were between 90 and 104\%, depending on the pesticide. The whole method uncertainty, assessed at 3 concentration levels under intra-laboratory reproducibility conditions, was below $25 \%$ for all tested pesticides. Hence, we optimized and validated a robust analytical method to quantify the target pesticides at low concentration levels in freshwater samples, with a simple, fast, and solventless desorption step. 
Keywords: Experimental designs; SBSE; thermal desorption; GC-MS/MS; measurement uncertainty; natural waters

\section{Introduction}

Since its introduction by Baltussen et al. in 1999 [1], stir bar sorptive extraction (SBSE) has become one of the most used miniaturized extraction and enrichment technique of organic contaminants in aqueous samples. This solventless technique is based on the same principles as solid phase microextraction (SPME). In other words, the extraction is governed by diffusion of the analytes and its efficiency relies on equilibrium, i.e., the partitioning of the analytes between the sample and the polydimethylsiloxane (PDMS) extraction phase [2]. But SBSE can achieve better extraction recoveries, especially for moderately hydrophobic analytes, as the volume of the extraction phase of the SBSE stir bars $(24 \mu \mathrm{L}$ to $126 \mu \mathrm{L})$ is much larger than the volume of the SPME fibers (up to $0.5 \mu \mathrm{L}$ ) [3, 4]. Stir bar sorptive extraction has been applied in pharmaceutical, biomedical, food, and environmental analysis for a wide range of organic chemicals, from polar endocrine disruptors (EDC) such as aromatic hydrocarbons (PAH) and polychlorobiphenyl (PCB) congeners. Several reviews covered in details the analytical applications of this technique [2, 4-6]. The extraction step is followed by desorption, either with organic solvent (liquid desorption, LD) or with heat (thermal desorption, TD) depending on the hydrophobicity and the thermal stability of the analytes, before analysis by liquid or gas chromatography. The optimization of the extraction conditions of organic chemicals in water samples has been carried out in several studies [713]. Desorption conditions need to be investigated as well, in order to achieve optimal back extraction of the analytes sorbed in the PDMS phase and yield maximal sensitivity and 
precision for the LC or GC analyses. Thermal desorption coupled with GC is more environmentally-friendly as it requires no organic solvent, and allows to reach lower limits of quantification as the whole amount of extracted analytes is transferred into the GC. For thermal desorption, the desorption time, the desorption temperature, the focusing temperature and the desorption flow are the most influential parameters.

Sanchez-Ortega et al. [11] and Camino-Sánchez et al. [12] performed step-by-step optimizations of the thermal desorption of some pesticides. However, this methodology does not allow to study the effect of the interaction of factors and guarantees to hit optimum conditions only if the studied factors are independent [14]. In case interactions between factors are important, only a multivariate approach allows to reach the real optimum, i.e., the best conditions for thermal desorption in this case [15]. This methodology has been used in very few studies for the optimization of the desorption of pesticides from SBSE stir bars. For instance, in order to determine the optimal liquid desorption conditions before the analysis of moderately hydrophobic to hydrophobic pesticides by liquid chromatography coupled with tandem mass spectrometry, Margoum et al. [13] realized an experimental design, which allowed them to investigate the effect of factors and the effect of their interactions on the selected response. Also, MacNamara et al. [15] used this methodology to optimize the parameters of extraction of organophosphorous pesticides from water, together with the parameters of thermal desorption. The use of such methodology for the optimization of the desorption of pesticides from SBSE stir bars, as well as for the optimization of other steps of analytical methods, might seem complex and time-consuming. In fact, quite the reverse, this approach is much faster than traditional one-variable-at-the-time (OVAT) methodology, as the effect of all the factors and the effect of their interactions are studied at the same time. Moreover, regarding thermal desorption optimization, all experiments of the design can be realized in the same analytical sample sequence. Nonetheless, didactical tutorials are needed 
to better describe this way of considering optimization and for a larger use of this powerful methodology.

In the present paper, we describe a complete multivariate optimization with the methodology of experimental designs. The aim of this work is to develop an analytical method consisting in SBSE followed by thermal desorption and gas chromatography coupled with tandem mass spectrometry (SBSE-TD-GC-MS/MS). Then, following comprehensive and thorough protocols, we validated the optimized method and determined the measurement uncertainties for the analysis of pesticides in freshwater samples. To realize this study, we selected a relevant set of 8 relatively hydrophobic to hydrophobic pesticides $\left(3.08<\log \mathrm{K}_{\mathrm{ow}}<4.96\right)$ usually encountered in freshwaters of agricultural watersheds. The extraction conditions have been developed and validated previously for liquid desorption followed by liquid chromatography coupled with tandem mass-spectrometry (SBSE-LD-LC-MS/MS) analysis [13]. In the present study, two experimental designs were conducted for the optimization of the thermal desorption of the selected pesticides. The effect of the desorption time, the desorption temperature, the desorption flow and the injector temperature, and the effect of their interactions were investigated with a screening experimental design. Then, the three most significant parameters were optimized by a second experimental design in order to reach maximal desorption of all selected pesticides. A third experimental design was realized to determine the best conditions for the thermal decontamination of the SBSE stir bars after the desorption step. Finally, the optimized method was validated regarding linearity, limit of quantification (LOQ), trueness and precision following a comprehensive validation procedure, and the analytical measurement uncertainty was assessed in conditions of intralaboratory reproducibility.

\section{Experimental}


104 Reagent and chemicals

106 The 8 selected pesticides (acetochlor (ATC), diflufenican (DFF), metolachlor (MTC),

107 chlorfenvinphos (CFV), chlorpyrifos-ethyl (CPE), chlorpyrifos-methyl (CPM), fenitrothion

108 (FNT), and procymidon (PCM)), the analytical standards, i.e., deuterated surrogates

109 (chlorpyrifos-ethyl d10 (CPE-d10) and fenitrothion d6 (FNT-d6)), and the internal standard

110 (hexabromobenzene (HBB)) were supplied by VWR (Strasbourg, France) and Sigma Aldrich

111 (Saint-Quentin Fallavier, France). Sodium chloride $\mathrm{NaCl}$ (purity $=99.5 \%$ ) was purchased

112 from VWR (Strasbourg, France).

113 GC grade methanol, acetonitrile, acetone, and dichloromethane were purchased from VWR

114 (Strasbourg, France). Ultrapure water was obtained using a Millipore water purification system equipped with a LC-Pak cartridge (Billerica, MA, USA).

116 The individual pesticide stock solutions were prepared in acetone at a concentration of 100

$117 \mathrm{mg} \mathrm{L}{ }^{-1}$ and stored at $4{ }^{\circ} \mathrm{C}$ for two months. Standard solutions for extraction were prepared 118 daily with ultrapure water by appropriate dilution of the stock solutions. Helium gas (purity = 119 99.999\%) used for thermal desorption and chromatographic analysis, nitrogen gas (purity $=$ $12099.995 \%$ ) used for thermal decontamination, and carbon dioxide gas (purity $=99.5 \%$ ) used 121 for focusing the desorbed pesticides in the cooled GC injector were purchased from Air 122 Liquide (Juhem, France).

124 Sample preparation and SBSE procedure

126 The extraction method was optimized and validated with spiked samples of ultrapure water,

127 Evian ${ }^{\circledR}$ mineral water, and surface water from two rivers in France (Saône River and Morcille 
128 River). Prior to SBSE, the river water samples were filtered under vacuum using $0.7-\mu \mathrm{m}$ glass

129 fiber filters (GF-F, Whatman).

130 The development and the validation of the extraction of the selected pesticides by SBSE have

131 been published elsewhere [13]. Briefly, the extraction of the pesticides was carried out with

132 SBSE stir bars (20 mm length $\times 1 \mathrm{~mm}$ film thickness with ca. $126 \mu \mathrm{L}$ of PDMS phase) from

133 Gerstel (Mülheim an der Ruhr, Germany). Before each use, the stir bars were thermally

134 conditioned at $50{ }^{\circ} \mathrm{C}$ for $24 \mathrm{~h}$, then rinsed in ultrasonic bath with $10 \mathrm{~mL}$ of

135 methanol/dichloromethane mixture $(50 / 50, \mathrm{v} / \mathrm{v})$ for $30 \mathrm{~min}$, and finally dried at $50{ }^{\circ} \mathrm{C}$ for $1 \mathrm{~h}$.

136 The extraction was performed on $20 \mathrm{~mL}$ of water samples with $2.0 \mathrm{~g}$ of $\mathrm{NaCl}$ at $800 \mathrm{rpm}$ for 3

137 h. After the extraction step, SBSE stir bars were gently rinsed with ultrapure water and dried

138 with Kimwipes ${ }^{\circledR}$ precision paper, then placed overnight at $-18{ }^{\circ} \mathrm{C}$ before chemical analysis.

140 Instrumentation and analytical conditions

142 Thermal desorption of the stir bars was performed with a CTC Analytics CombiPal

143 Autosampler (Zwingen, Switzerland), equipped with a desorption oven. During the desorption

144 phase, the desorption oven was directly connected to a programmable temperature

145 vaporization (PTV) injector, which was installed in a Varian 3800 GC (Bruker, Marne-la-

146 Vallée, France).

147 Stir bars were placed in empty glass tubes for thermal desorption, spiked with $5 \mu \mathrm{L}$ of

148 hexabromobenzene at $20 \mathrm{mg} \mathrm{L}^{-1}$ in acetone as internal standard prior to analysis. The analytes

149 were desorbed from the stir bars in the optimized conditions and focused, by carbon dioxide

150 cooling when needed, in a liner packed with deactivated glass wool at the optimized PTV

151 injector temperature in split mode. The split is located at the bottom of the PTV injector,

152 which means the whole part of pesticides desorbed from the stir bars in the desorption oven is 
153 focused in the liner, whatever the split ratio. The PTV injector was then ramped at $200{ }^{\circ} \mathrm{C}$

$154 \mathrm{~min}^{-1}$ to a final temperature of $280{ }^{\circ} \mathrm{C}$ (held for $10 \mathrm{~min}$ ) and the analytes were transferred into

155 a Zebron ZB-5ms capillary column (30 m x $0.25 \mathrm{~mm}$ x $0.25 \mu \mathrm{m})$ provided by Phenomenex

156 (Le Pecq, France). The carrier gas was helium at a flow rate of $1.0 \mathrm{~mL} \mathrm{~min}^{-1}$. The column

157 oven was programmed at the same temperature as the injector during $10 \mathrm{~min}$, ramped at $30{ }^{\circ} \mathrm{C}$

$158 \min ^{-1}$ to $180{ }^{\circ} \mathrm{C}$, at $5{ }^{\circ} \mathrm{C} \min ^{-1}$ to $240{ }^{\circ} \mathrm{C}$, at $10{ }^{\circ} \mathrm{C} \min ^{-1}$ to $280{ }^{\circ} \mathrm{C}$, and finally at $30{ }^{\circ} \mathrm{C} \min ^{-1}$ to

$159300{ }^{\circ} \mathrm{C}$ and held for $5 \mathrm{~min}$, for a total analysis time of $36 \mathrm{~min}$. After thermal desorption and

160 during the chromatographic separation of the analytes, the SBSE stir bars were kept in the

161 desorption oven for thermal decontamination with nitrogen gas under the optimized

162 conditions, to insure total elimination of pesticide residues. Each SBSE stir bar was desorbed

163 and decontaminated for $60 \mathrm{~min}$.

164 The mass detector Varian 4000MS (Bruker, Marne-la-Vallée, France) was an ion trap 165 equipped with an external source operated in electronic impact ionization mode at $70 \mathrm{eV}$, and

166 the analytes were monitored in MS/MS mode except for hexabromobenzene, which was

167 detected in SIS (selected ion storage) mode. The MS/MS settings of the selected pesticides

168 and the surrogates were determined by automatic optimization using MS Workstation

169 software (version 6.9), assisted by manual optimization. Two types of collision-induced

170 dissociation (CID) of the target pesticides were investigated, resonant CID and non-resonant

171 CID. Resonant CID is more compound specific and more energetic than non-resonant CID. It

172 is originally more adapted to stable parent ions such as PAH, PCB, dioxins and furans. For

173 these two types of CID, two types of waveforms were applied to the ion trap (Table 1). In

174 resonant mode, waveforms represent the application of low voltage and high frequency

175 whereas, in non-resonant mode, high voltage and low frequency are applied. The

176 identification of the selected pesticides was performed with the retention time, the

177 quantification transition and the mass spectrum of the fragmentation products (Table 1). 
179 Experimental designs for method optimization

181 The optimization of the thermal desorption parameters was realized in two sequential 182 experimental designs. Statgraphics software (Centurion XV.II) from SigmaPlus was used for 183 data processing. Firstly, a fractional factorial design $2^{4} \times 3 / 4$ was realized for screening 184 purpose (Design $\mathrm{n}^{\circ} 1$ ). In this design, 4 factors with 2 levels (low level (-1)) and high level 185 (+1)) were investigated, which represent, for a full factorial design, $2^{4}$ experiments. We planned to realize 3 quarters of these experiments, with 2 additional experiments at the center

187 point of all factors (medium level (0)), making a block of 14 experiments. This block was 188 repeated once for a total of 28 experiments and 16 degrees of freedom for the experimental 189 error. The low level, the center point and the high level of each factor investigated in design $\mathrm{n}^{\circ} 1$ are presented in Table 2 . We selected this design in order to obtain the same information as from a classical full factorial design, but with a smaller number of experiments. In other

192 words, both designs allow the evaluation of the effect of the factors and the effect of the two193 factor interactions, with enough degrees of freedom for the experimental error; but the

194 fractional design comprises 28 experiments, whereas a full factorial design replicated twice (2 195 blocks) with 2 center points per block needs 36 experiments. The effect of the desorption 196 time, the desorption temperature, the desorption flow, the injector temperature, and the effect 197 of their interactions on the pesticide chromatographic peak areas were evaluated and rated, in 198 order to identify and select the most influential factors.

199 Secondly, the most 3 influential factors (the desorption temperature, the desorption flow, the 200 injector temperature) were selected and optimized with a Box Behnken design (Design $n^{\circ} 2$ ). 201 In this design, the 3 factors with 3 levels (low level (-1)), medium level (0) and high level $202(+1)$ ) were investigated in 12 experiments. Three experiments at the center point of all factors 
(medium level (0)) were added, making a block of 15 experiments. This block was repeated once for a total of 30 experiments and 19 degrees of freedom for the experimental error. This design allows the determination of response surfaces with fewer experiments than a $3^{3}$ full factorial design (30 herein versus 54 in a full factorial design replicated twice, i.e., 2 blocks), but provides enough degrees of freedom to evaluate the experimental error. Fig. 1a and Fig. 1b show respectively graphical representations of the Box Behnken design and the $3^{3}$ full factorial design as cubes. The three axes of the cubes represent the 3 thermal desorption factors to be optimized, with their levels (low level (-1), medium level (0), and high level $(+1)$ ), and the dots represent the experiments of the designs. For the graphical representation of the Box Behnken design, the experiments are located at the middle of each edge of the cube, so 12 experiments. The dots at the center of the cube represent the 3 experiments added

214 at the center point of all 3 factors, so a total of 15 dots. For the graphical representation of the $3^{3}$ full factorial design, the experiments are located at each corner ( 8 experiments), at the middle of each edge (12 experiments), at the middle of each face (6 experiments) and at the center of the cube ( 1 experiment), so a total of 27 experiments. These 27 experiments 218 represent all 27 combinations of the 3 levels of 3 factors.

219 The 3 levels of each factor investigated in design $n^{\circ} 2$ were the same as those for design $n^{\circ} 1$ 220 (Table 2), except for the desorption temperature, which were 220,260 and $300{ }^{\circ} \mathrm{C}$. Design $\mathrm{n}^{\circ} 1$ revealed that the desorption temperature had a positive effect on the desorption of the studied pesticides. Therefore, we decided to investigate the effect of this factor at higher 223 temperatures. Changing the levels of the factors had no impact on the interpretation of design $224 \mathrm{n}^{\circ} 2$ as the data of the two designs were processed separately. Also, according to the results of 225 the design $\mathrm{n}^{\circ} 1$, this might result in higher desorption of all studied pesticides. The high level 
advised by Gerstel. For both experimental designs, the blocks represented two different days for chemical analysis.

In addition, the optimal conditions for the thermal decontamination of the SBSE stir bars after the desorption step were investigated with a third experimental design (Design $n^{\circ} 3$ ). Another Box Behnken design was carried out (1 block, 3 center points, and 3 factors with 3 levels for a

232 total of 15 experiments and 9 degrees of freedom for the experimental error). The 3 levels of 233 each factor investigated in design $n^{\circ} 3$ are presented in Table 3 . In this experiment, we investigated the effect of the decontamination temperature, the decontamination time, and the amount of pesticides in the SBSE stir bar on the decontamination efficiency. The amount of pesticides in the stir bars was controlled by extraction of water samples of different pesticide 237 concentrations. Depending on the pesticide, the concentrations in water samples varied, but 238 were set for each pesticide as 50 times the respective LOQ $(50 \times$ LOQ $)$ for the low level, $2391025 \times$ LOQ for the center point, and $2000 \times$ LOQ for the high level. For design $\mathrm{n}^{\circ} 3$, the 240 responses were the pesticide chromatographic peak areas of the subsequent analysis of the 241 SBSE stir bars. In other words, the SBSE stir bars used for the extraction of water samples 242 spiked with all the pesticides at different concentrations were thermally desorbed for analysis 243 and decontaminated under each set of the conditions established in the experimental design; 244 then, they were thermally desorbed a second time for analysis in order to determine the 245 amounts of pesticides remaining after the thermal decontamination step of the first analysis.

247 Validation of the optimized SBSE-TD-GC-MS/MS method

249 Although it is essential to ensure robustness and reliability of an analytical method, the 250 validation is often performed only partially or in non-representative conditions, so 251 performance results may be inapplicable to real samples. For instance, limits of detection 
(LOD) and LOQ may be underestimated when determined in standard solutions because matrix effects are not considered. These limits may also be underestimated when evaluated with signal-to-noise $(\mathrm{S} / \mathrm{N})$ ratios, as they only represent instrumental limits and repeatability is usually not evaluated [16]. Moreover, trueness and precision of the extraction recoveries are usually determined at a single level of spiking, although they may vary along the concentration range. Measurement uncertainty is an estimation of the error on the analytical result taking into account sources of variability such as the preparation of the samples, the sample matrix, and the day of the analysis. It represents the interval in which the true concentration value of a real sample can be expected [13].

The method validation was inspired from standard methods ISO/IEC 17025:2005 and AFNOR NF T90-210:2009 [17, 18], and previous validations of LC-MS/MS methods [13, 19]. Measurement uncertainty of the analytical method was assessed according to standard methods ISO 11352:2012 and AFNOR XP T 90-220:2003 [20, 21], and previous validation of an LC-MS/MS method [13].

Study of the linearity range

For each selected pesticide, two adjacent calibration ranges (a low concentration range and a

270 high concentration range, with one common concentration level) were investigated. Each

271 calibration curve was constituted with pesticide standard solutions prepared in ultrapure water

272 and extracted by SBSE. Each calibration range was composed of 6 concentration levels, 273 which could be different depending on the pesticide. The linearity of the method was 274 statistically tested with 5 calibration curves. All these curves were obtained through extraction 275 of ultrapure water samples spiked with the selected pesticides. Linearity was validated when 276 the correlation coefficient $\left(\mathrm{R}^{2}\right)$ of each calibration curve $(5 \times 2$ curves per pesticide) and their 
mean value were higher than 0.990 and the deviation between theoretical and calculated standard concentration values were lower than the maximal acceptable deviation (MAD). These MAD were fixed for each concentration level from $10 \%$ to $60 \%$ (60\% for the lowest concentration level, at LOQ level).

Verification of the limits of quantification

The LOQ was first estimated, then it was verified experimentally for each pesticide. First, the account, this instrumental LOQ were corrected with a security factor $(k=5)$. For each compound, this theoretical limit of quantification $\left(\mathrm{LOQ}_{\mathrm{th}}\right)$ was verified by spiking and analyzing water samples $(\mathrm{n}=10)$. Mean concentration $(\overline{\mathrm{LOQ}})$ and standard deviation $\left(\mathrm{s}_{\mathrm{LOQ}}\right)$ were calculated and compared to an MAD fixed at $60 \%$ of the $\mathrm{LOQ}_{\mathrm{th}}$. For each pesticide, the two following equations had to be verified:

$$
\begin{aligned}
& \overline{\mathrm{LOQ}}-2 \times \mathrm{s}_{\mathrm{LOQ}}>\mathrm{LOQ}_{\mathrm{th}}-60 \% \times \mathrm{LOQ}_{\mathrm{th}} \\
& \overline{\mathrm{LOQ}}+2 \times \mathrm{s}_{\mathrm{LOQ}}<\mathrm{LOQ}_{\mathrm{th}}+60 \% \times \mathrm{LOQ}_{\text {th }}
\end{aligned}
$$

Trueness and precision

The trueness and precision of the method were assessed at LOQ level, at a medium concentration level, and at a high concentration level of the calibration curves. For each pesticide, the LOQ level and the medium concentration level were on the low concentration range curve, whereas the high concentration level was on the high concentration range curve.

298 Five duplicates of water samples were spiked at each concentration level, and mean recoveries and the corresponding relative standard deviations (RSD) were determined under 
within-laboratory reproducibility conditions $[20,21]$. Mean recoveries were determined with calibration curves constituted with pesticide standard solutions prepared in water and extracted by SBSE.

\section{Measurement uncertainty}

306 Three operators prepared spiked water samples with 3 types of water (Evian® mineral water, and surface waters from 2 rivers in France); then the extractions of the water samples and the analyses were performed on different days. The measurement uncertainty was assessed for the

310 level, at a medium concentration level, and at a high concentration level. Ten triplicates for

311 each concentration level $(\mathrm{n} \times \mathrm{p}=30)$ were realized under intra-laboratory reproducibility

313 performed on the experimental results; then the repeatability variance $\left(\mathrm{s}_{\text {repeat }}^{2}\right)$ and the

314 reproducibility variance $\left(\mathrm{s}_{\text {repro }}^{2}\right)$ were determined as follows:

$$
\begin{gathered}
\mathrm{s}_{\text {repeat }}^{2}=\frac{\sum_{\mathrm{i}=1}^{\mathrm{p}} \sum_{\mathrm{j}=1}^{\mathrm{n}}\left(\mathrm{x}_{\mathrm{ij}}-\overline{\mathrm{x}_{\mathrm{i}}}\right)^{2}}{(\mathrm{n}-1) \mathrm{p}} \\
\mathrm{s}_{\text {repro }}^{2}=\frac{\sum_{\mathrm{i}=1}^{\mathrm{p}} \mathrm{n}\left(\overline{\mathrm{x}_{\mathrm{i}}}-\overline{\overline{\mathrm{x}}}\right)^{2}}{\mathrm{n}(\mathrm{p}-1)}+\frac{(\mathrm{n}-1) \mathrm{s}_{\text {repeat }}^{2}}{\mathrm{n}}
\end{gathered}
$$

315 where $\mathrm{p}=10, \mathrm{n}=3, \mathrm{x}_{\mathrm{ij}}$ is the calculated concentration for a sample, $\overline{\mathrm{x}_{\mathrm{i}}}$ is the average

316 calculated concentration for one triplicate, and $\overline{\bar{x}}$ is the average of all 30 calculated 317 concentrations.

318 Finally, the measurement uncertainty (U) was calculated as follows with an expanded 319 coverage factor $(\mathrm{k})$ of 2 : 


$$
\mathrm{U}(\%)=\frac{\mathrm{k} \times \mathrm{s}_{\text {repro }}}{\overline{\mathrm{x}}} \times 100
$$

\section{Results and discussion}

Experimental designs

Screening of the desorption parameters by a fractional factorial design (Design $n^{\circ} 1$ )

Table 4 shows the experimental design and the experimental matrix composed of 8 columns as responses (pesticide areas) and 28 rows for the experiments, obtained from the analyses of stir bars under the thermal desorption conditions set by the experimental design. A Principal Component Analysis (PCA) was applied to this data matrix (previously mean-centered) with

Statgraphics software. The first vector explained $74 \%$ of the total variance of the experimental results; and all variables (the chromatographic peak areas of the studied pesticides) had

334 positive loadings on this vector (Fig. 2a). This means that all studied pesticides had similar 335 behaviors regarding the thermal desorption. Therefore, we considered the score of each experiment on this vector (Fig. 2b) as a global response (to be maximized). This methodology

337 for determination of a global response has been previously used in the successful optimization 338 of a SBSE-TD-GC analysis of 7 pesticides in water [15]. On Fig. 2b, each experiment has a 339 score on the first vector and on the second vector, and is represented by a "+" symbol. The 340 two experiments which obtained the best scores on the first vector are experiments $\mathrm{n}^{\circ} 2$ and $341 \mathrm{n}^{\circ} 16$ (Table 4). For both experiments, the thermal desorption conditions were desorption 342 temperature at $280^{\circ} \mathrm{C}$, desorption flow at $75 \mathrm{~mL} \cdot \mathrm{min}^{-1}$ for $10 \mathrm{~min}$ with the injector 
temperature at $60{ }^{\circ} \mathrm{C}$. Therefore, the results of the PCA could give an indication on the

344 conditions which result in high desorption of the pesticide.

345 The statistical analysis of this screening design, with the score on the first vector as response,

346 showed that there was no significant experimental error and no significant difference in the

347 results of the experiments of the two blocks. The model obtained, with $\mathrm{R}^{2}=0.97$, is the

348 following:

$\mathrm{Y}=20.3-0.42 \mathrm{~A}\left({ }^{* * *}\right)-0.06 \mathrm{~B}\left(^{* * *}\right)-1.00 \mathrm{C}\left({ }^{* * *}\right)-0.15 \mathrm{D}\left(^{* * *}\right)+0.001 \mathrm{AB}\left({ }^{* * *}\right)+0.02 \mathrm{AC}\left({ }^{* * *}\right)+$

$\left.0.002 \mathrm{AD}^{* * * *}\right)+0.0003 \mathrm{BC}+0.00003 \mathrm{BD}+0.009 \mathrm{CD}\left(^{* * *}\right)$

where $\mathrm{A}=$ Desorption flow, $\mathrm{B}=$ Desorption temperature, $\mathrm{C}=$ Desorption time, and $\mathrm{D}=$ Injector temperature, and $\mathrm{AB}, \mathrm{AC}, \mathrm{AD}, \mathrm{BC}, \mathrm{BD}, \mathrm{CD}$ are their two-factor interactions. The significant terms in the model are marked with stars: $\left(^{*}\right)$ means p-values $<0.05,\left({ }^{* *}\right)$ means pvalues $<0.01$, and $\left(^{* * *}\right)$ means p-values $<0.001$. So, in this case, a very high level of significance was obtained. Not only the effects of all 4 factors were significant, but also the effects of 4 interactions were significant, which could not have been observed with an OVAT optimization methodology. Moreover, two of these interactions were even quite unexpected.

359 Indeed, one can note the significance of $\mathrm{AD}$ and $\mathrm{CD}$, two interactions that involve factors 360 from different parts of the analytical system (desorption oven and PTV injector). The 361 statistical analysis of the design showed that all factors and interactions had positive effect on 362 the response. This means that the desorption flow, temperature and time, and the injector 363 temperature have to be set at their higher levels for maximum response. Moreover, regarding 364 the interactions, the effect of an increase of desorption temperature, for instance, is greater when desorption flow is at higher level. 
Optimization of thermal desorption (Design $n^{\circ} 2$ ) and decontamination (Design $n^{\circ} 3$ ) by Box

Behnken designs

On the basis of the results of design $\mathrm{n}^{\circ} 1$, we decided to set the desorption time at $10 \mathrm{~min}$, the

maximal level tested, without performing further optimization for higher values, in order to

372 keep the total analysis time at 60 min maximum. Thus, the optimization of the thermal

373 desorption was realized with the injector temperature (Factor A), the desorption flow (Factor

B), and the desorption temperature (Factor C). Table 5 shows the Box Behnken experimental was applied to the experimental results of the design $n^{\circ} 2$ (previously mean-centered) and showed that all the variables have positive loading on the first vector (Fig. 3a), which explained $77 \%$ of the variance. Therefore, we considered the score of each experiment on the same vector (Fig. 3b) as a global response (to be maximized). On Fig. 3b, the two these values confirm the results of the PCA realized with the data of design $n^{\circ} 1$.

384 The model, obtained with $\mathrm{R}^{2}=0.98$ and leading to the response surface shown in Fig. 4 , is the 385 following: $\mathrm{Y}=35.1-0.48 \mathrm{~A}\left({ }^{* * *}\right)-0.37 \mathrm{~B}\left({ }^{* * *}\right)-0.18 \mathrm{C}\left({ }^{* * *}\right)+0.002 \mathrm{AA}\left(^{* * *}\right)+0.004 \mathrm{AB}\left(^{* * *}\right)+$ $\left.0.0007 \mathrm{AC}^{* *}\right)+0.002 \mathrm{BB}+0.0004 \mathrm{BC}+0.0003 \mathrm{CC}\left(^{*}\right)$

The evaluation of the effects of the main factors and the effect of their interactions led to the 


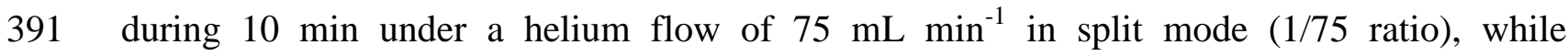

392 maintaining a focusing temperature of $60{ }^{\circ} \mathrm{C}$ in the PTV injector of the GC-MS/MS system.

393 Another Box Behnken design was realized to optimize the conditions of thermal

394 decontamination (Design $n^{\circ} 3$ ) of the SBSE stir bars after desorption (Table 3). Only traces of 395 chlorpyrifos-methyl, with area equivalent to the area of blank samples, were detected in the

396 second GC-MS/MS analyses of the stir bars corresponding to the highest concentration level

397 tested during the experimental design. Therefore, the optimized conditions for the thermal 398 decontamination of the SBSE stir bars were the highest point in the experimental space, i.e., $300{ }^{\circ} \mathrm{C}$ for $50 \mathrm{~min}$.

400

Advantages of the experimental design approach

402

The first advantage of a multivariate approach over an OVAT approach is the time saved for

404 the whole experimentation process. Indeed, for screening purposes, building an experimental design implies defining all the factors that can have an effect on the response studied before realizing any experiment. Whether in OVAT approach, usually, only the factors that the 407 operator believes will have an effect are tested [14]. Moreover, contrary to what is commonly 408 thought, fewer experiments are needed in an experimental design to obtain the same -or more 409 information- as for an OVAT approach. For instance, in our case, 28 experiments were 410 performed to study at the same time the effect of 4 factors and the effect of their interactions, 411 at 2 levels, in two blocks and to assess the experimental error. If the same study is performed 412 with an OVAT approach, triplicates are usually needed to assess the experimental error. 413 Therefore, to obtain the same level of information (excluding the effect of the interaction of 414 the factors), 48 experiments would be necessary. 
415 Also, screening designs allow to assess the significance of factors and to select the most significant ones regarding the response in a non-arbitrary way. Another advantage of our experimental design is the study of interactions between factors. In case factors are interdependent, an OVAT approach does not guarantee to reach the real optimum. Moreover, unexpected significant interactions might be detected [14].

420 Finally, in the present study, the data matrix of 8 columns as responses and 28 rows for the experiments allowed to realize a robust PCA and to obtain reliable information regarding the behaviors of the tested pesticides during the thermal desorption step.

Performances and validation of the analytical method

The results of the validation of the analytical method are reported in Table 6. Excellent linearity was observed for all calibration curves $\left(R^{2} \geq 0.9972\right)$ and the deviation between theoretical and calculated standard concentrations was between $10 \%$ for the highest concentration level and $60 \%$ for the lowest one.

The LOQ in water were validated in accordance with Eq. 1 and Eq. 2; they ranged from 2.5 $431 \mathrm{ng} \mathrm{L^{-1 }}$ for chlorpyrifos-methyl to $50 \mathrm{ng} \mathrm{L}^{-1}$ for diflufenican. Based only on $\mathrm{S} / \mathrm{N}$ ratios of 10 , instrumental LOQ ranged from 0.05 to $10 \mathrm{ng} \mathrm{L}^{-1}$. But, we validated LOQ in different water matrices while ensuring required trueness and repeatability. Our method allowed to obtain 434 LOQ which are more relevant for the routine analysis of unknown freshwater samples. These 435 LOQ are in agreement or up to 5-fold higher than those reached in previous SBSE-TD-GC436 MS/MS analytical methods for chlorpyrifos-methyl, chlorpyrifos-ethyl, chlorfenvinphos, 437 fenitrothion, and metolachlor in water samples $[12,22]$. In those methods, however, either the 438 type of water used for the determination of the LOQ was not specified or the LOQ were 439 instrumental (i.e., an S/N ratio of 10). To our knowledge, the SBSE-TD-GC-MS/MS analysis 
440 of moderately hydrophobic to hydrophobic pesticides $\left(3.80<\log \mathrm{K}_{\mathrm{ow}}<4.20\right)$ with different 441 physical chemical properties such as procymidon, acetochlor, and diflufenican in water 442 samples has not been reported in the literature.

443 For all selected pesticides and all concentration levels, mean recoveries, determined with

444 calibration curves constituted with pesticide standard solutions prepared in water samples and

445 extracted by SBSE, ranged from 90 to $104 \%$ (Table 6). Satisfactory global inter-day 446 precision, estimated at each concentration level as RSD of 10 determinations on spiked water 447 samples, was between 5.2 and $17.4 \%$.

448 Results on measurement uncertainty are reported in Table 6. For all selected pesticides at the 449 three concentration levels, satisfactory measurement uncertainty for SBSE-TD-GC-MS/MS 450 was obtained $(\mathrm{U} \leq 25 \%)$. To our knowledge, very few validations of SBSE-TD-GC-MS/MS methods have included studies of the uncertainty of the analytical results [12, 23]. Regarding the pesticides studied herein, Camino-Sánchez et al. [12] reported uncertainties ranging from 40 to $46 \%$ for chlorfenvinphos, chlorpyrifos-ethyl, chlorpyrifos-methyl, fenitrothion, and metolachlor; but the uncertainties were determined with another approach on which very few details were presented. In our method, 90 water samples were used for the determination of 456 realistic uncertainties under intra-laboratory reproducibility conditions, i.e., with 3 types of water, at 3 concentration levels, prepared by 3 operators and analyzed at different days.

458 Results showed for all target pesticides homogeneous uncertainty across the concentration range. Margoum et al. [13] used the same approach for the evaluation of uncertainties on the

460 analysis of 15 pesticides by SBSE-LD-LC-MS/MS. We obtained similar uncertainty values 461 for the analysis of pesticides targeted by both methods, i.e., chlorfenvinphos, chlorpyrifos462 ethyl, diflufenican, fenitrothion, and procymidon.

463 In comparison with the SBSE-LD-LC-MS/MS method developed and validated by Margoum 
TD-GC-MS/MS method, partly because the whole amount of pesticides sorbed in the SBSE stir bar is transferred into the GC for chemical analysis. Moreover, thermal desorption allows much faster and easier sample treatment. After the extraction step, the SBSE stir bar is simply placed into desorption tube for online thermal desorption and GC-MS/MS analysis, instead of substantial extra time for offline liquid desorption and preparation of the sample to be injected into the LC. Finally, thermal desorption and decontamination allow dramatic reduction of organic solvent consumption.

\section{Conclusion}

Experimental design is a powerful approach for optimization of analytical method and the larger is the number of factors to be evaluated, the more this approach is necessary for a comprehensive, simple and fast study. As the use of such methodology is mistakenly thought complex and time-consuming, didactic tutorials are needed to better describe it. In this study, we used two sequential experimental designs for the optimization of the desorption conditions of an SBSE-TD-GC-MS/MS method for the determination of 8 selected pesticides in 481 freshwaters. Design $\mathrm{n}^{\circ} 1$ allowed a screening of the effect of the desorption time, the desorption temperature, the desorption flow, the injector temperature, and the effect of their interactions on the peak areas of the target pesticides as responses. Design $n^{\circ} 2$ resulted in the optimization of the 3 desorption parameters that proved to be influential by the screening

485 design to obtain maximal responses (i.e., the desorption temperature, the desorption flow and 486 the injector temperature). We developed and validated a robust and reliable analytical method 487 for simple, fast, and environmentally-friendly analysis of agricultural pesticides in 488 freshwaters. 
489 In this study, a set of 8 moderately hydrophobic to hydrophobic pesticides $\left(3.08<\log \mathrm{K}_{\mathrm{ow}}<\right.$

490 4.96) was used for the optimization of the analytical method by means of experimental

491 designs. As this interesting approach should be applied for other method optimizations,

492 further work will focus on adding other hydrophobic micropollutants in this SBSE-TD-GC-

493 MS/MS method.

494

495

\section{Acknowledgements}

497

498 The authors thank the French National Research Agency (ANR) through PoToMAC project 499 (ANR 2011 CESA 022 02) and the French National Agency for Water and Aquatic 500 Environments (ONEMA) via the AQUAREF programme for financial support. 
501 Table 1. Retention time and mass spectrometry detection conditions of the selected pesticides

\begin{tabular}{|c|c|c|c|c|c|c|c|}
\hline Compound & Abbreviation & $\begin{array}{l}\text { Retention time } \\
(\mathrm{min})\end{array}$ & $\begin{array}{l}\text { Scan } \\
\text { type }\end{array}$ & $\begin{array}{l}\text { Quantification transition } \\
(\mathrm{m} / \mathrm{z})\end{array}$ & $\begin{array}{c}\text { Waveform } \\
\text { type }\end{array}$ & $\begin{array}{c}\text { Excitation } \\
\text { amplitude (V) }\end{array}$ & $\begin{array}{c}\text { Excitation storage } \\
\text { level }(\mathrm{m} / \mathrm{z})\end{array}$ \\
\hline Acetochlor & $\overline{\text { ATC }}$ & 19.1 & MS/MS & $223>146$ & non-resonant & 65 & 98.2 \\
\hline Chlorpyrifos-methyl & CPM & 19.1 & MS/MS & $286>208$ & resonant & 1.06 & 126 \\
\hline Fenitrothion $d 6^{\mathrm{a}}$ & FNT-d6 & 19.8 & MS/MS & $283>266$ & non resonant & 44 & 77.9 \\
\hline Fenitrothion & FNT & 19.9 & MS/MS & $277>260$ & non resonant & 63 & 122.0 \\
\hline Metolachlor & MTC & 20.2 & MS/MS & $238>162$ & non resonant & 73 & 104.8 \\
\hline Chlorpyrifos-ethyl & CPE & 20.3 & MS/MS & $314>258$ & non resonant & 82 & 138.3 \\
\hline Chlorpyrifos-ethyl d10 & CPE-d10 & 20.2 & MS/MS & $324>260$ & non resonant & 87 & 142.7 \\
\hline Chlorfenvinphos & $\mathrm{CFV}$ & 21.5 & MS/MS & $323>267$ & non resonant & 85 & 142.3 \\
\hline Procymidon & PCM & 21.7 & MS/MS & $283>255$ & non resonant & 64 & 93.5 \\
\hline \multirow[t]{2}{*}{ Diflufenican } & DFF & 26.3 & MS/MS & $394>266$ & non resonant & 98 & 173.6 \\
\hline & & $\begin{array}{l}\text { Retention time } \\
(\mathrm{min})\end{array}$ & $\begin{array}{l}\text { Scan } \\
\text { type }\end{array}$ & $\begin{array}{l}\text { High mass } \\
(\mathrm{m} / \mathrm{z})\end{array}$ & - & - & - \\
\hline Hexabromobenzene ${ }^{b}$ & HBB & 27.2 & SIS & 558 & - & - & - \\
\hline
\end{tabular}

$502 \quad{ }^{a}$ : deuterated surrogates

$503{ }^{\mathrm{b}}:$ internal standard 
504 Table 2. Factor levels of the experimental design for the screening of the desorption 505 conditions (Design $\mathrm{n}^{\circ} 1$ )

\begin{tabular}{lccc}
\hline Factors & Low level $(-1)$ & Center point $(0)$ & High level $(+1)$ \\
\hline $\mathrm{A}=$ injector temperature $\left({ }^{\circ} \mathrm{C}\right)$ & 20 & 40 & 60 \\
$\mathrm{~B}=$ desorption flow $\left(\mathrm{mL} \mathrm{min}^{-1}\right)$ & 50 & 62 & 75 \\
$\mathrm{C}=$ desorption temperature $\left({ }^{\circ} \mathrm{C}\right)$ & 200 & 240 & 280 \\
$\mathrm{D}=$ desorption time $(\min )$ & 2 & 6 & 10 \\
\hline
\end{tabular}

506

508 Table 3. Factor levels of the Box Behnken design for the optimization of the decontamination 509 conditions (Design $\mathrm{n}^{\circ} 3$ )

\begin{tabular}{lccc}
\hline Factors & Low level $(-1)$ & Center point $(0)$ & High level $(+1)$ \\
\hline $\mathrm{A}=$ concentration $\left(\mu \mathrm{g} \mathrm{L}^{-1}\right)$ & $50 \times \mathrm{LOQ}$ & $1025 \times \mathrm{LOQ}$ & $2000 \times \mathrm{LOQ}$ \\
$\mathrm{B}=$ decontamination temperature $\left({ }^{\circ} \mathrm{C}\right)$ & 250 & 275 & 300 \\
$\mathrm{C}=$ decontamination time $(\mathrm{min})$ & 10 & 30 & 50 \\
\hline
\end{tabular}

511 
Table 4. Experimental matrix and experimental results of the fractional factorial design $\left(\right.$ Design $\left.\mathrm{n}^{\circ} 1\right)$

\begin{tabular}{|c|c|c|c|c|c|c|c|c|c|c|c|c|c|}
\hline Experiment & Block & $\begin{array}{c}\text { Injector } \\
\text { temperature } \\
\left({ }^{\circ} \mathrm{C}\right) \\
\end{array}$ & $\begin{array}{c}\text { Desorption } \\
\text { flow } \\
\left.(\mathrm{mL} \mathrm{min})^{-1}\right) \\
\end{array}$ & $\begin{array}{c}\text { Desorption } \\
\text { temperature } \\
\left({ }^{\circ} \mathrm{C}\right) \\
\end{array}$ & $\begin{array}{c}\text { Desorption } \\
\text { time } \\
(\mathrm{min}) \\
\end{array}$ & $\begin{array}{r}\text { ATC } \\
\text { peak area }\end{array}$ & $\begin{array}{r}\mathrm{CPM} \\
\text { peak area }\end{array}$ & $\begin{array}{r}\text { FNT } \\
\text { peak area }\end{array}$ & $\begin{array}{r}\text { MTC } \\
\text { peak area }\end{array}$ & $\begin{array}{r}\mathrm{CPE} \\
\text { peak area }\end{array}$ & $\begin{array}{r}\mathrm{CFV} \\
\text { peak area }\end{array}$ & $\begin{array}{r}\text { PCM } \\
\text { peak area }\end{array}$ & $\begin{array}{r}\text { DFF } \\
\text { peak area }\end{array}$ \\
\hline 1 & 1 & 20 & 75 & 280 & 2 & 3006 & 19700 & 2112 & 10874 & 3740 & 1367 & 205 & 821 \\
\hline 2 & 1 & 60 & 75 & 280 & 10 & 962055 & 5214000 & 105104 & 3470000 & 130000000 & 182270 & 45335 & 23446 \\
\hline 3 & 1 & 20 & 50 & 200 & 2 & 268 & 1865 & 143 & 885 & 394 & 101 & 0 & 0 \\
\hline 4 & 1 & 60 & 50 & 200 & 2 & 6930 & 71808 & 488 & 6110 & 2745 & 0 & 0 & 0 \\
\hline 5 & 1 & 60 & 50 & 200 & 10 & 1080000 & 4311000 & 115693 & 2404000 & 872149 & 7124 & 3901 & 489 \\
\hline 6 & 1 & 20 & 50 & 200 & 10 & 7504 & 66923 & 3747 & 20879 & 8027 & 2682 & 356 & 572 \\
\hline 7 & 1 & 40 & 62 & 240 & 6 & 165808 & 1388000 & 7194 & 227874 & 71975 & 8794 & 1740 & 3270 \\
\hline 8 & 1 & 60 & 50 & 280 & 2 & 14916 & 116536 & 1398 & 18364 & 5899 & 558 & 43 & 173 \\
\hline 9 & 1 & 20 & 50 & 280 & 2 & 345 & 2664 & 294 & 1793 & 777 & 461 & 41 & 130 \\
\hline 10 & 1 & 40 & 62 & 240 & 6 & 134764 & 979366 & 5998 & 206702 & 65104 & 8893 & 1707 & 3021 \\
\hline 11 & 1 & 20 & 50 & 280 & 10 & 9305 & 84364 & 5238 & 33076 & 11233 & 4698 & 808 & 1960 \\
\hline 12 & 1 & 20 & 75 & 200 & 10 & 48521 & 338867 & 19963 & 169133 & 58556 & 21124 & 4656 & 7761 \\
\hline 13 & 1 & 60 & 75 & 200 & 2 & 36344 & 215214 & 2281 & 62032 & 19776 & 1475 & 192 & 313 \\
\hline 14 & 1 & 60 & 50 & 280 & 10 & 860073 & 5431000 & 112792 & 2283000 & 774930 & 15099 & 9718 & 3150 \\
\hline 15 & 2 & 20 & 75 & 280 & 2 & 6884 & 38811 & 5422 & 42140 & 11193 & 4477 & 724 & 2858 \\
\hline 16 & 2 & 60 & 75 & 280 & 10 & 1413000 & 4568000 & 228150 & 5266000 & 2238000 & 179632 & 67296 & 33093 \\
\hline 17 & 2 & 20 & 50 & 200 & 2 & 259 & 1397 & 138 & 1333 & 370 & 135 & 20 & 0 \\
\hline 18 & 2 & 60 & 50 & 200 & 2 & 1522 & 10747 & 336 & 3437 & 958 & 0 & 17 & 32 \\
\hline 19 & 2 & 60 & 50 & 200 & 10 & 991152 & 5719000 & 71488 & 2341000 & 668062 & 4558 & 1996 & 873 \\
\hline 20 & 2 & 20 & 50 & 200 & 10 & 10300 & 84100 & 5101 & 37308 & 11362 & 2517 & 495 & 889 \\
\hline 21 & 2 & 40 & 62 & 240 & 6 & 113284 & 763604 & 10430 & 206159 & 48236 & 6575 & 1676 & 4815 \\
\hline 22 & 2 & 60 & 50 & 280 & 2 & 10645 & 80398 & 1239 & 20310 & 5321 & 391 & 63 & 248 \\
\hline 23 & 2 & 20 & 50 & 280 & 2 & 605 & 3896 & 502 & 3510 & 1135 & 557 & 46 & 171 \\
\hline 24 & 2 & 40 & 62 & 240 & 6 & 105681 & 801857 & 9745 & 197716 & 46892 & 6806 & 1595 & 3525 \\
\hline 25 & 2 & 20 & 50 & 280 & 10 & 16040 & 120690 & 7356 & 57314 & 17259 & 3590 & 846 & 2600 \\
\hline 26 & 2 & 20 & 75 & 200 & 10 & 44737 & 312874 & 20824 & 194372 & 54717 & 13411 & 3230 & 6227 \\
\hline 27 & 2 & 60 & 75 & 200 & 2 & 22736 & 128949 & 2332 & 52309 & 10789 & 1184 & 219 & 533 \\
\hline 28 & 2 & 60 & 50 & 280 & 10 & 1219000 & 4678000 & 190144 & 1944 & 999080 & 10338 & 7416 & 3294 \\
\hline
\end{tabular}


Table 5. Experimental matrix and experimental results of the Box Behnken design (Design ${ }^{\circ}$ 2), with desorption time set at 10 min

\begin{tabular}{|c|c|c|c|c|c|c|c|c|c|c|c|c|}
\hline Experiment & Block & $\begin{array}{c}\text { Injector } \\
\text { temperature } \\
\left({ }^{\circ} \mathrm{C}\right) \\
\end{array}$ & 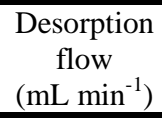 & $\begin{array}{c}\text { Desorption } \\
\text { temperature } \\
\left({ }^{\circ} \mathrm{C}\right) \\
\end{array}$ & $\begin{array}{r}\text { ATC } \\
\text { peak area }\end{array}$ & $\begin{array}{r}\mathrm{CPM} \\
\text { peak area }\end{array}$ & $\begin{array}{r}\text { FNT } \\
\text { peak area }\end{array}$ & $\begin{array}{r}\text { MTC } \\
\text { peak area }\end{array}$ & $\begin{array}{r}\mathrm{CPE} \\
\text { peak area }\end{array}$ & $\begin{array}{r}\text { CFV } \\
\text { peak area }\end{array}$ & $\begin{array}{r}\mathrm{PCM} \\
\text { peak area }\end{array}$ & $\begin{array}{r}D F F \\
\text { peak area }\end{array}$ \\
\hline 1 & 1 & 40 & 62 & 260 & 402432 & 2305000 & 26532 & 1189000 & 359449 & 25332 & 6008 & 10328 \\
\hline 3 & 1 & 40 & 75 & 220 & 816051 & 4766000 & 88298 & 3254000 & 831925 & 52561 & 14291 & 19155 \\
\hline 4 & 1 & 40 & 50 & 300 & 351868 & 2916000 & 16715 & 620746 & 174898 & 14285 & 3569 & 5677 \\
\hline 5 & 1 & 60 & 62 & 300 & 1389000 & 5196000 & 222121 & 5369000 & 2551000 & 147391 & 66787 & 17832 \\
\hline 6 & 1 & 40 & 75 & 300 & 1219000 & 5082000 & 104682 & 4186000 & 1293000 & 70306 & 19599 & 49130 \\
\hline 7 & 1 & 20 & 62 & 220 & 35272 & 304485 & 15084 & 175043 & 65034 & 15374 & 4976 & 7013 \\
\hline 8 & 1 & 40 & 50 & 220 & 182666 & 1536000 & 7483 & 278088 & 85803 & 5643 & 1466 & 1524 \\
\hline 9 & 1 & 20 & 50 & 260 & 15264 & 137156 & 8585 & 74295 & 25303 & 6108 & 1603 & 3009 \\
\hline 10 & 1 & 40 & 62 & 260 & 639403 & 4262000 & 31484 & 1427000 & 360825 & 26009 & 6525 & 10140 \\
\hline 11 & 1 & 20 & 62 & 300 & 42701 & 353515 & 16389 & 215010 & 72104 & 24180 & 6475 & 19714 \\
\hline 12 & 1 & 60 & 75 & 260 & 1155000 & 6337000 & 240588 & 5362000 & 2581000 & 341391 & 101966 & 32259 \\
\hline 14 & 1 & 60 & 50 & 260 & 1121000 & 4700000 & 96157 & 3851000 & 1409000 & 15784 & 9755 & 3005 \\
\hline 15 & 1 & 60 & 62 & 220 & 1360000 & 5155000 & 163109 & 5335000 & 2434000 & 61109 & 40279 & 6724 \\
\hline 16 & 2 & 40 & 62 & 260 & 680290 & 3924000 & 34797 & 1620000 & 403961 & 24843 & 6714 & 13616 \\
\hline 17 & 2 & 40 & 62 & 260 & 716657 & 4670000 & 42254 & 1705000 & 441991 & 26891 & 8460 & 13508 \\
\hline 18 & 2 & 40 & 75 & 220 & 1071000 & 5503000 & 83920 & 3280000 & 867038 & 46513 & 14183 & 21676 \\
\hline 19 & 2 & 40 & 50 & 300 & 332811 & 2365000 & 14301 & 629835 & 162180 & 14449 & 3146 & 7124 \\
\hline 20 & 2 & 60 & 62 & 300 & 1472000 & 5171000 & 228192 & 5787000 & 2752000 & 130074 & 64149 & 23875 \\
\hline 21 & 2 & 40 & 75 & 300 & 1337000 & 4956000 & 130785 & 4624000 & 1427000 & 73377 & 23657 & 59909 \\
\hline 22 & 2 & 20 & 62 & 220 & 40271 & 320914 & 14911 & 191722 & 74888 & 16002 & 4360 & 8217 \\
\hline 23 & 2 & 40 & 50 & 220 & 71532 & 608192 & 3880 & 105372 & 35862 & 2310 & 523 & 605 \\
\hline 24 & 2 & 20 & 50 & 260 & 7441 & 78472 & 3619 & 31827 & 12827 & 1992 & 494 & 1241 \\
\hline 25 & 2 & 40 & 62 & 260 & 360639 & 2823000 & 16597 & 665452 & 198594 & 11518 & 3198 & 5354 \\
\hline 26 & 2 & 20 & 62 & 300 & 24792 & 181799 & 11360 & 116406 & 41647 & 12668 & 2709 & 7672 \\
\hline 27 & 2 & 60 & 75 & 260 & 1405000 & 4924000 & 2332 & 6045000 & 3031000 & 162260 & 77801 & 21696 \\
\hline 29 & 2 & 60 & 50 & 260 & 1086000 & 6691000 & 73336 & 2831000 & 1011000 & 5106 & 2675 & 1054 \\
\hline 30 & 2 & 60 & 62 & 220 & 977287 & 6391000 & 161530 & 3691000 & 1568000 & 15483 & 10521 & 2514 \\
\hline
\end{tabular}


Table 6. Linear dynamic range, regression coefficient, mean recovery and relative standard deviation $(\mathrm{n}=10)$, and measurement uncertainty $(\mathrm{n} \times \mathrm{p}=30)$ at 3 concentration levels

\begin{tabular}{|c|c|c|c|c|c|c|c|c|c|c|c|}
\hline \multirow[b]{2}{*}{ Compound } & \multirow[b]{2}{*}{$\begin{array}{l}\text { Concentration } \\
\text { range } \\
\left(\mu \mathrm{g} \mathrm{L}^{-1}\right)\end{array}$} & \multirow[b]{2}{*}{$\begin{array}{c}\text { Regression } \\
\text { coefficient } \\
\left(\mathrm{R}^{2}\right)\end{array}$} & \multicolumn{3}{|c|}{ LOQ level } & \multicolumn{3}{|c|}{ Medium level } & \multicolumn{3}{|c|}{ High level } \\
\hline & & & $\begin{array}{c}\text { Spiked } \\
\text { concentration } \\
\left(\mu \mathrm{g} \mathrm{L}^{-1}\right)\end{array}$ & $\begin{array}{c}\text { Mean } \\
\text { recovery } \\
(\mathrm{RSD})(\%) \\
(\mathrm{n}=10)\end{array}$ & $\begin{array}{c}\mathrm{U}(\%) \\
(\mathrm{k}=2) \\
(\mathrm{n} \times \mathrm{p}=30)\end{array}$ & $\begin{array}{c}\text { Spiked } \\
\text { concentration } \\
\left(\mu \mathrm{g} \mathrm{L}^{-1}\right)\end{array}$ & $\begin{array}{c}\text { Mean } \\
\text { recovery } \\
(\mathrm{RSD})(\%) \\
(\mathrm{n}=10)\end{array}$ & $\begin{array}{c}\mathrm{U}(\%) \\
(\mathrm{k}=2) \\
(\mathrm{n} \times \mathrm{p}=30)\end{array}$ & $\begin{array}{c}\text { Spiked } \\
\text { concentration } \\
\left(\mu \mathrm{g} \mathrm{L}^{-1}\right)\end{array}$ & $\begin{array}{c}\text { Mean } \\
\text { recovery } \\
(\mathrm{RSD})(\%) \\
(\mathrm{n}=10)\end{array}$ & $\begin{array}{c}\mathrm{U}(\%) \\
(\mathrm{k}=2) \\
(\mathrm{n} \times \mathrm{p}=30)\end{array}$ \\
\hline Acetochlor & $0.005-10$ & 0.9985 & 0.005 & $100.8(8.8)$ & 16.9 & 0.2 & $93.7(8.7)$ & 16.7 & 0.8 & $90.3(9.3)$ & 20.4 \\
\hline Chlorfenvinphos & $0.025-50$ & 0.9972 & 0.025 & $104.2(17.4)$ & 20.3 & 1.0 & $94.2(5.2)$ & 12.8 & 4.0 & $101.7(9.0)$ & 14.4 \\
\hline Chlorpyrifos-ethyl & $0.025-50$ & 0.9989 & 0.025 & $96.3(9.4)$ & 18.7 & 1.0 & 94.9 (7.6) & 15.5 & 4.0 & $97.4(6.6)$ & 9.5 \\
\hline Chlorpyrifos-methyl & $0.0025-5$ & 0.9980 & 0.0025 & $94.3(11.9)$ & 20.8 & 0.1 & $96.5(8.2)$ & 14.5 & 0.4 & $96.5(6.6)$ & 11.5 \\
\hline Diflufenican & $0.05-100$ & 0.9980 & 0.05 & $98.5(12.0)$ & 25.0 & 2.0 & $102.7(7.3)$ & 14.3 & 8.0 & $97.4(8.2)$ & 16.6 \\
\hline Fenitrothion & $0.005-10$ & 0.9985 & 0.005 & $98.3(12.5)$ & 23.0 & 0.2 & $96.8(8.2)$ & 14.4 & 0.8 & $93.2(8.5)$ & 16.1 \\
\hline Metolachlor & $0.005-10$ & 0.9992 & 0.005 & $95.3(7.6)$ & 14.7 & 0.2 & $97.4(7.5)$ & 14.0 & 0.8 & $97.5(8.0)$ & 12.6 \\
\hline Procymidon & $0.005-10$ & 0.9992 & 0.005 & $98.9(9.3)$ & 18.6 & 0.2 & $101.5(7.0)$ & 12.9 & 0.8 & $97.8(9.4)$ & 15.3 \\
\hline
\end{tabular}

LOQ: limit of quantification; RSD: relative standard deviation; U: measurement uncertainty; k: expanded coverage factor 

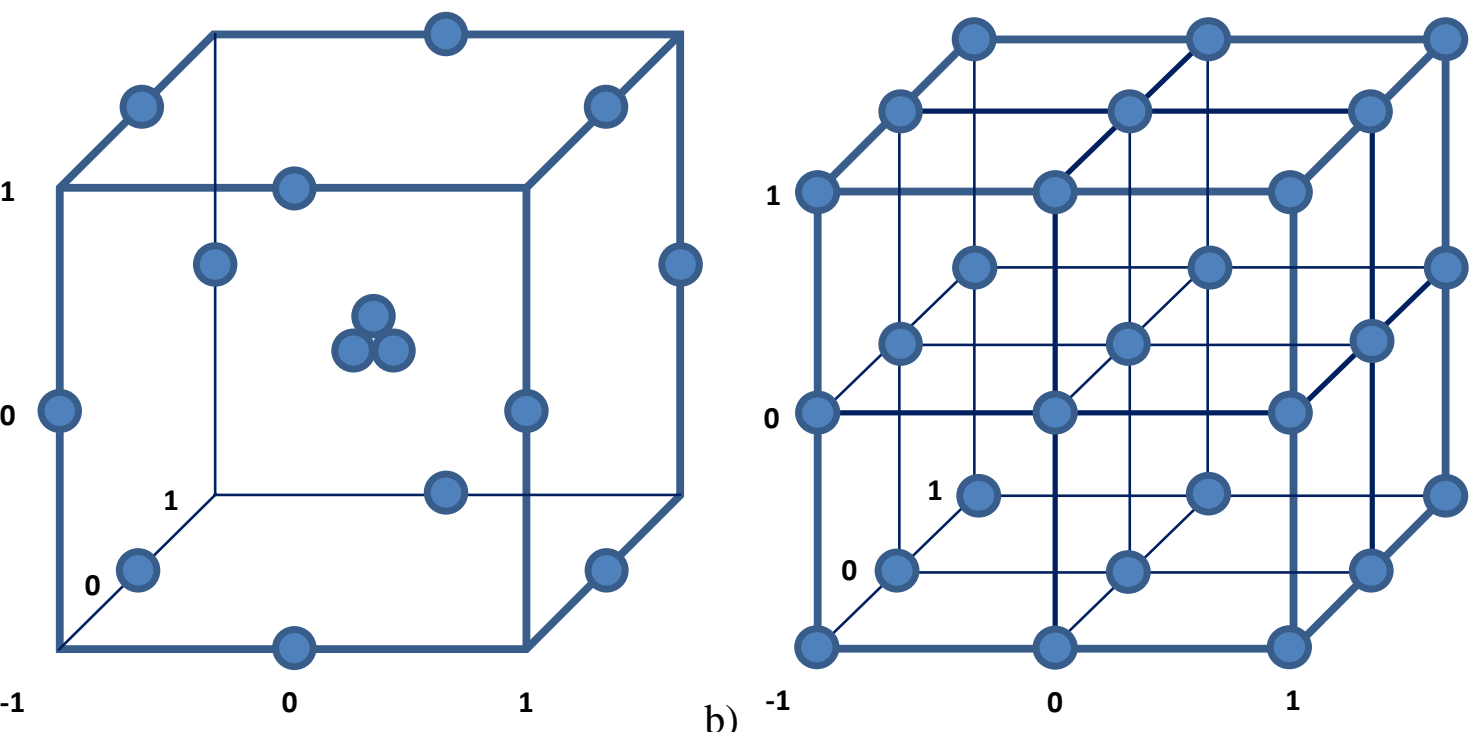

2 Fig. 1 Graphical representations of a Box Behnken design (a) and a full factorial $3^{3}$ design (b). 3 The three axes of the cubes represent the three thermal desorption factors to be optimized, 4 with their levels $(-1=$ low level, $0=$ medium level, and $1=$ high level $)$, and the dots represent 5 the experiments of the designs 

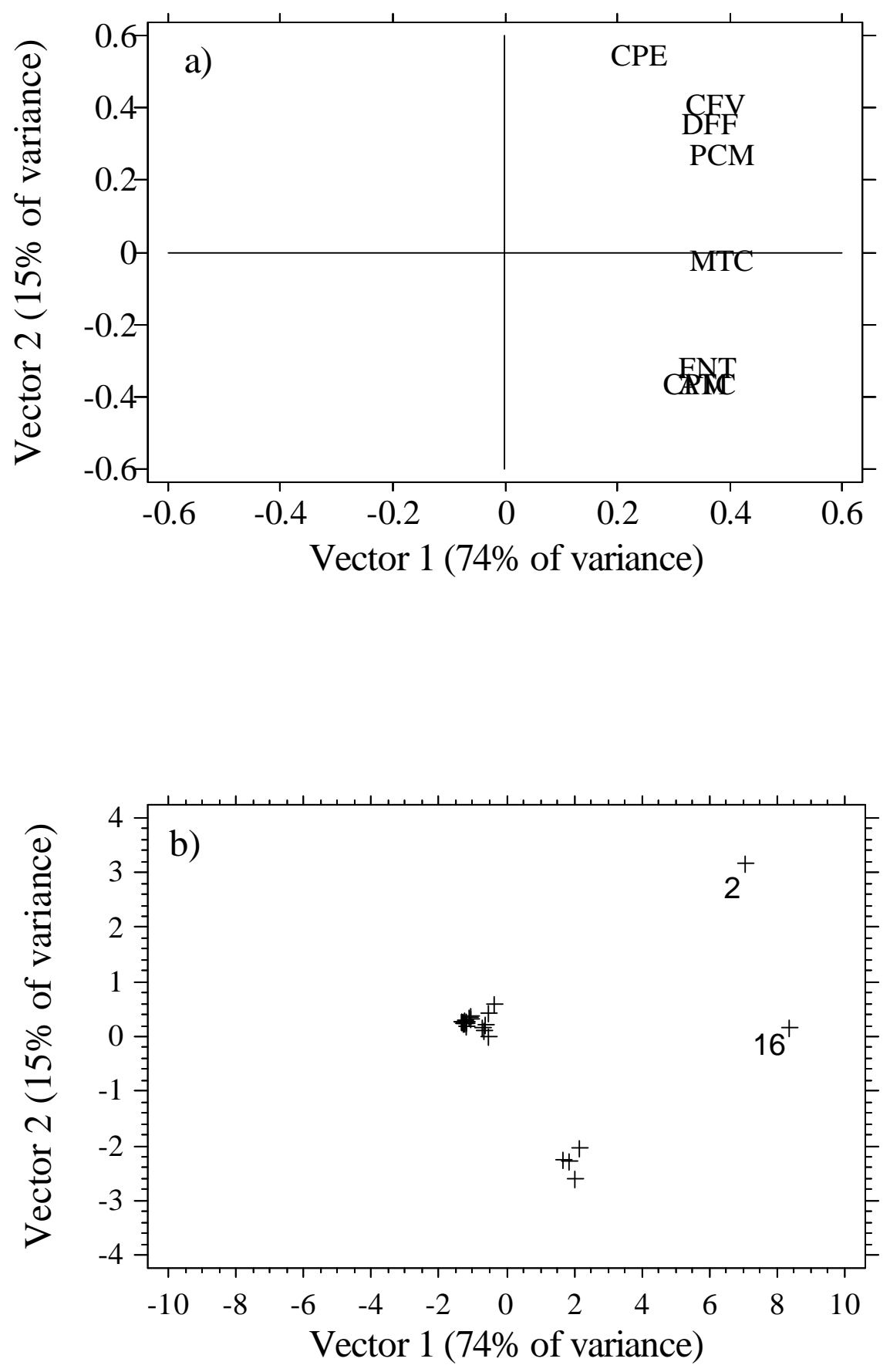

9 Fig. 2 Loading plot (a) of the studied pesticides and score plot (b) of the experiments of the 10 PCA on the results of design $\mathrm{n}^{\circ} 1$. On the score plot, the numbers next to the " + " symbols are 11 the numbers of the experiments which obtained the best scores on vector 1 

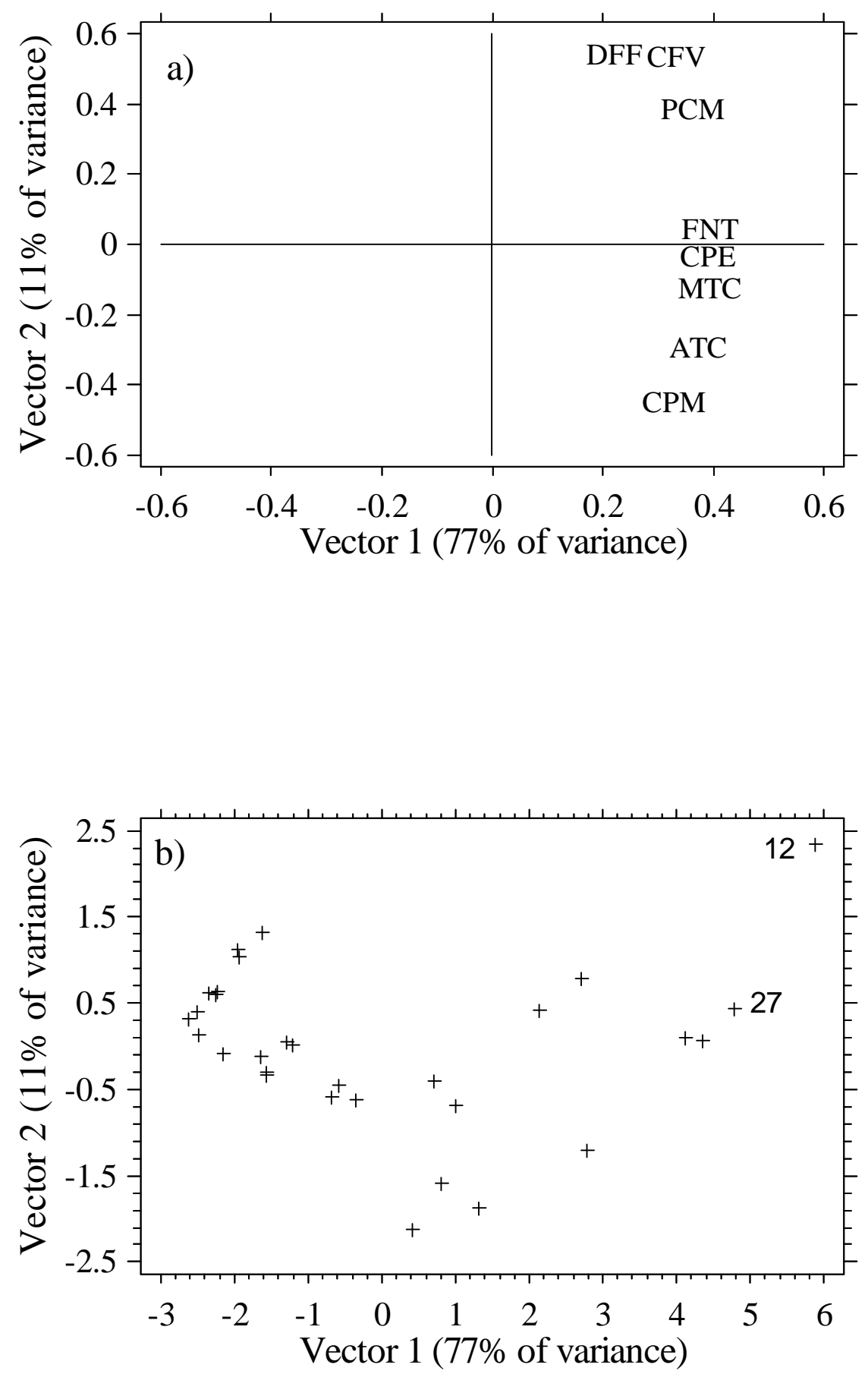

13

14 Fig. 3 Loading plot (a) of the studied pesticides and score plot (b) of the experiments of the 15 PCA on the results of design $\mathrm{n}^{\circ} 2$. On the score plot, the numbers next to the " + " symbols are 16 the numbers of the experiments which obtained the best scores on vector 1 


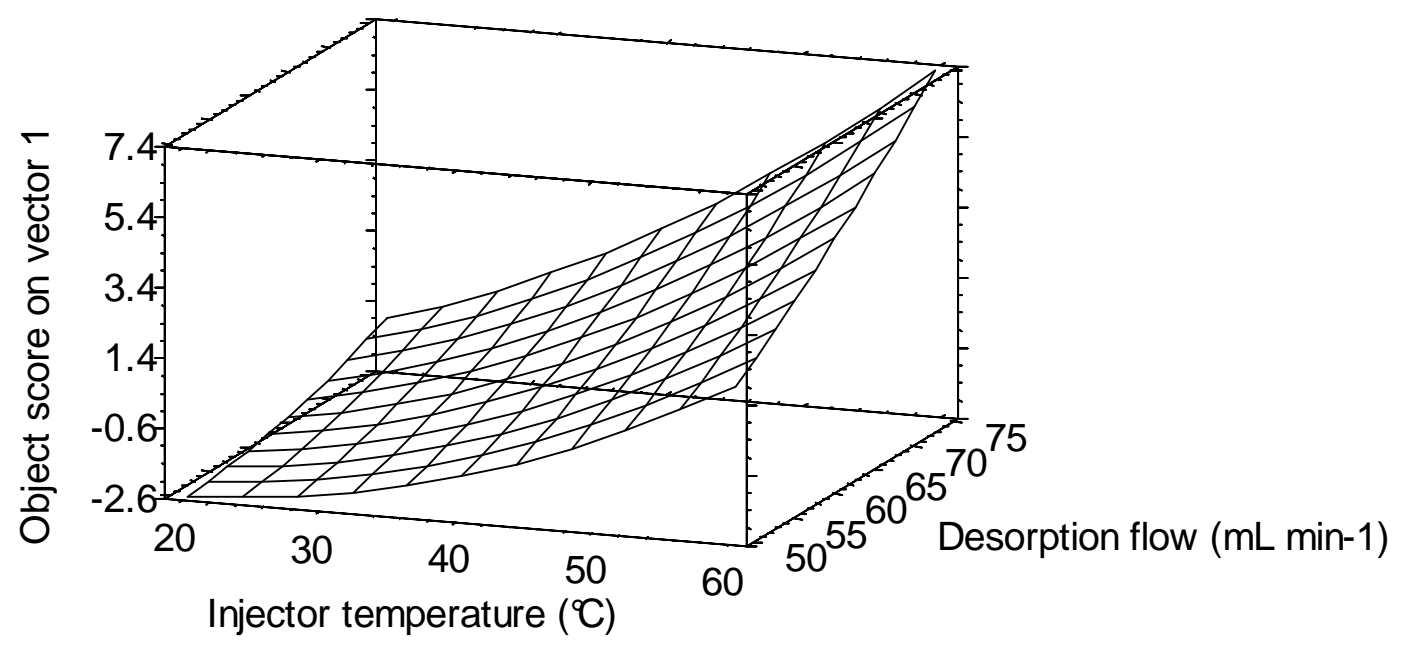

Fig. 4 Response surface of the Box Behnken design for the optimization of the desorption conditions (Design $\mathrm{n}^{\circ}$ ). The chart plots the effect of the injector temperature and the desorption flow on the object score on vector 1 (i.e., global response for the 8 studied pesticides), with the desorption temperature set at $300{ }^{\circ} \mathrm{C}$ and the desorption time set at 10 min 


\section{References}

1. Baltussen E, Sandra P, David F, Cramers C (1999) J Microcol Sep 11:737-747

2. David F, Sandra P (2007) J Chromatogr A 1152:54-69

3. Blasco C, Fernández M, Picó Y, Font G (2004) J Chromatogr A 1030:77-85

4. Kawaguchi M, Ito R, Saito K, Nakazawa H (2006) J Pharmaceut Biomed 40:500-508

5. David F, Tienpont B, Sandra P (2003) LC GC Europe 16

6. Sanchez-Rojas F, Bosch-Ojeda C, Cano-Pavon J (2009) Chromatographia 69:S79-S94

7. Prieto A, Basauri O, Rodil R, Usobiaga A, Fernandez LA, Etxebarria N, Zuloaga O (2010) J Chromatogr A 1217:2642-2666

8. Nakamura S, Daishima S (2005) Anal Bioanal Chem 382:99-107

9. Ochiai N, Sasamoto K, Kanda H, Nakamura S (2006) J Chromatogr A 1130:83-90

10. Guerrero ED, Castro Mejías R, Marín RN, Barroso CG (2007) J Chromatogr A 1165:144-150

11. Sanchez-Ortega A, Unceta N, Gómez-Caballero A, Sampedro MC, Akesolo U, Goicolea MA, Barrio RJ (2009) Anal Chim Acta 641:110-116

12. Camino-Sánchez FJ, Zafra-Gómez A, Cantarero-Malagón S, Vílchez JL (2012) Talanta 89:322-334

13. Margoum C, Guillemain C, Yang X, Coquery M (2013) Talanta, 116:1-7

14. Leardi R (2009) Anal Chim Acta 652:161-172

15. MacNamara K, Leardi R, McGuigan F (2009) Anal Chim Acta 636:190-197

16. Miège C, Bados P, Brosse C, Coquery M (2009) TrAC, Trends Anal Chem 28:237-244

17. ISO/IEC 17025:2005. General requirements for the competence of testing and calibration laboratories (2005) 30p

18. AFNOR NF T90-210. Qualité de l'eau - Protocole d'évaluation initiale des performances d'une méthode dans un laboratoire (2009) 43p

19. Gabet-Giraud V, Miege C, Herbreteau B, Hernandez-Raquet G, Coquery M (2010) Anal Bioanal Chem 396:1841-1851

20. ISO 11352:2012. Water quality - Estimation of measurement uncertainty based on validation and quality control data (2012) $26 \mathrm{p}$

21. AFNOR XP T90-220. Qualité de l'eau - Protocole d'estimation de l'incertitude de mesure associée à un résultat d'analyse pour les méthodes physico-chimiques (2003) 73p

22. Huertas C, Morillo J, Usero J, Gracia-Manarillo I (2007) Talanta 72:1149-1156

23. León VM, Llorca-Pórcel J, Álvarez B, Cobollo MA, Muñoz S, Valor I (2006) Anal Chim Acta 558:261-266 